\title{
Author Spotlight: Maria Chiara Cianci
}

\section{Maria Chiara Cianci ${ }^{1}$}

Accepted: 20 April 2021 / Published online: 24 June 2021

(c) The Author(s), under exclusive licence to Springer Science+Business Media, LLC, part of Springer Nature 2021

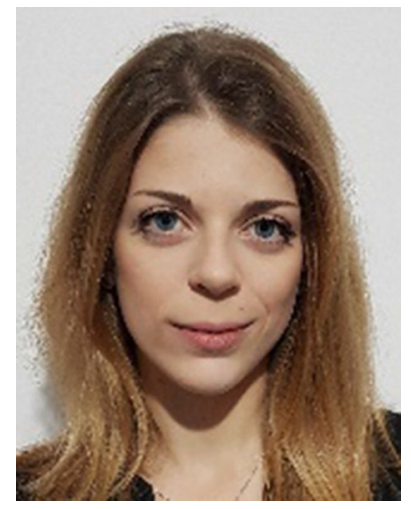

and research interests include surgical gastroenteric disease and their impact on the paediatric population. Her aim is to become academic paediatric surgeon.

Publisher's Note Springer Nature remains neutral with regard to jurisdictional claims in published maps and institutional affiliations.

Dr. Maria Chiara Cianci (mariachiara.cianci@ unifi.it) is currently a Resident in Paediatric Surgery at the Meyer Childrens Hospital, University of Florence (Italy). Her clinical

Maria Chiara Cianci

mariachiara.cianci@unifi.it

1 Firenze, Italy 